\title{
Radiofrequency Monitoring of Intracranial Hemorrhage in the Neurological Intensive Care Unit: A Pilot Trial of the SENSE Device
}

5 Joseph J. Korfhagen ${ }^{1}$ PhD, George J. Shaw ${ }^{1,2, *}$ MD, PhD, Matthew L. Flaherty ${ }^{1,3}$ MD

6 Opeolu Adeoye ${ }^{1,4}$ MD, William A. Knight ${ }^{4}$ MD

7

$8 \quad{ }^{1}$ SENSE Diagnostics, Inc., Cincinnati, OH

$9{ }^{2}$ Department of Biomedical Engineering, University of Cincinnati, Cincinnati, $\mathrm{OH}$

$10{ }^{3}$ Department of Neurology, University of Cincinnati, Cincinnati, $\mathrm{OH}$

$11{ }^{4}$ Department of Emergency Medicine, University of Cincinnati, Cincinnati, OH

12 Corresponding Author, Email: gshaw@senseneuro.com 


\section{Introduction}

Intracerebral hemorrhage ( $\mathrm{ICH})$ is a devastating form of stroke with mortality of 35 to $52 \%$. Only $20 \%$ of survivors experience full recovery by 6 months (1), and ICH prevalence is expected to rise with the aging population. Current therapy is predominantly supportive (2), although there have been encouraging early results from neuro-interventional trials $(3,4)$ of stereotactic thrombolysis and acute blood pressure control (Shi 2017). Other approaches include hemostatic agents and coagulation factors with mixed results to date (5).

Hemorrhage expansion (HE) in $\mathrm{ICH}$ is associated with worse neurologic outcome and increased mortality (6). Davis et al found that for every $1 \mathrm{ml}$ increase in $\mathrm{ICH}$ volume, patients were $7 \%$ more likely to worsen from independence towards requiring assistance, and from assistance to poor outcome. HE is not uncommon, occurring in about $38 \%$ of ICH patients within 20 hours (7).

Currently, HE is detected by repeat neuroimaging with CT or MRI, and can lead to significant changes in patient management such as surgical intervention (8). Monitoring for HE after ICH is currently performed by clinical neurological exam and periodic neuroimaging. Clinical exam can be problematic in patients that are sedated and/or intubated. The exam can also lag serious intracranial events. In addition, at most institutions, the patient must be transported to radiology for the imaging which can take substantial time and risk. Finally, none of these techniques can be considered a continuous monitor of the brain and the hemorrhage. There are no current techniques or devices to provide continuous, non-invasive, bedside ICH monitoring in clinical practice.

The SENSE (Sensor Evaluation of Neurological Status in Emergencies) device was developed to address this clinical need. SENSE is a radiofrequency (RF) based technique utilizing the differential scattering and absorption of radio waves from intracranial tissues of 
varying dielectric constant $\varepsilon$ and conductivity $\sigma(9)$. Specifically, blood differs substantially in its electrical properties as compared with the grey and white matter of the brain (10). An RF signal incident on a blood collection of differing $\varepsilon$ and $\sigma$ from the surrounding tissue induces a time oscillating electric dipole moment in the blood collection (11). This results in a signal generated by the blood collection at the same frequency f of the incident signal, but differing in phase and amplitude, depending on the differing electrical characteristics, location of the blood, and its volume. These combined signals can be measured, and used to determine the presence or absence of significant changes in blood volume over time.

The use of microwaves as a potential medical imaging modality has been under development for some time (Semenov 2009). In microwave tomography (MT), microwave signals are scattered from biological tissues. The scattered signal amplitudes are used as input data to invert Maxwell's equations, and obtain $\square$ as a function of position within the tissue. Limitations include low dielectric contrast between some soft tissues, and mathematical complexity in solving these equations to obtain $\square$. Other approaches such as AI based analysis have been used in interpreting the scattered signals (Persson 2014) in more focused applications, such as the detection of acute stroke. Overall, these techniques have been focused on imaging or acute diagnosis of general brain pathology, and not as a monitor of changes in such pathology.

Korfhagen et al (Korfhagen 2013) demonstrated that a $400 \mathrm{MHz}$ RF signal could detect as little as $1 \mathrm{ml}$ of blood in a validated in-vitro brain gel model. They also found that the RF signal scattering was dependent on the geometry of the experimental blood collection. Kandadai et al (Kandadai 2014) demonstrated RF detection of $3 \mathrm{ml}$ of blood in a porcine ICH preparation over a frequency range of $0.4-1 \mathrm{GHz}$. In addition, they found that the optimal RF frequency for intracranial blood detection was within $0.75-1 \mathrm{GHz}$ range.

The overall goal of this study was to determine if SENSE could be used safely to monitor and detect ICH expansion in the Neurocritical Care unit. The secondary objective was to determine if SENSE could detect hemorrhage expansion of $3 \mathrm{ml}$ or greater in these patients.

\section{Materials and Methods}

\section{Study Objectives}

The overall objective of this prospective, observational, single site, first-in-human pilot study of the SENSE device was to determine if SENSE could safely monitor ICH in the clinical environment. Up to 10 patients could be enrolled. Secondary objectives included human factors information to optimize the design, and operator challenges in the clinical environment. The results of the study were intended to guide further design changes for a planned pivotal clinical trial of the device.

The primary endpoint for this early feasibility study was the correlation of SENSE with CT changes over time. An expansion of $3 \mathrm{ml}$ or more in a given ICH was considered significant.

\section{Study Population}

The study population was patients presenting with a diagnosis of spontaneous ICH to a single urban comprehensive stroke center (CSC). Emergency Department based Clinical Research Coordinators (CRC) screened for ICH patients at the study site. Patients were enrolled within 24 hours of symptom onset. 
medRxiv preprint doi: https://doi.org/10.1101/2020.05.25.20109108; this version posted May 26, 2020. The copyright holder for this preprint (which was not certified by peer review) is the author/funder, who has granted medRxiv a license to display the preprint in perpetuity. It is made available under a CC-BY-NC-ND 4.0 International license .

In order to be a candidate for the study, ICH patients were 22 years of age or older, with a diagnostic head CT performed within 24 hours of symptom onset, an $\mathrm{ICH}$ volume greater than or equal to 1 and less than $90 \mathrm{ml}$, and able to participate in study procedures. Potential subjects were excluded if pregnant or lactating, had a history of seizure disorder or were on medications that lowered the seizure threshold, had an intraventricular hemorrhage (IVH), subdural hemorrhage (SDH), epidural hemorrhage $(\mathrm{EDH})$, or secondary cause of the ICH, if surgical ICH evacuation or continuous EEG monitoring was planned within 24 hours, or if taking medications that increased hemorrhage risk.

Patients were approached by CRCs after the screening process, and enrolled after appropriate written informed consent was obtained from the patient, or approved legal surrogate. Following subject enrollment, the SENSE device was placed on the patient for up to 72 hours. The device performed a scan every 10 minutes, and an individual scan took about 40 seconds. The SENSE data was recorded internally in the device, and later downloaded by study personnel after the monitoring period was complete for a given subject. The treating clinicians were blinded to the SENSE data.

For each subject, data recorded included basic subject demographic data, past medical history, and radiologist's interpretation of the neuroimaging studies. Adverse events (AE) and serious adverse events (SAEs) were noted and recorded.

The study protocol was approved by the FDA under and IDE and by the local IRB.

\section{Imaging Protocol}

The following CT imaging protocol was followed for each subject:

- Diagnosis: CT Scan 1 - standard of care; diagnostic head CT scan within 24 hours of symptom onset.

- First Study CT: CT Scan 2 - study CT; first study CT scan as soon as practicable after informed consent, followed by SENSE monitoring within 15 minutes of completion of the first CT scan.

- 12 Hours: CT Scan 3 - standard of care; CT scan $12( \pm 6)$ hours after first study CT scan.

- 72 Hours: CT Scan 4 - study CT; end of study CT scan $72( \pm 12)$ hours after first study CT scan.

Study eligibility ICH volumes were calculated from the diagnostic CT by clinical and/or research staff using the ABC method (12). Subsequently, ICH and edema volumes were determined by a neuroradiologist blinded to the clinical and SENSE device data. Quantification of volumes were performed using computer-assisted methods. The blinded evaluator was required to place seedpoints within the volume of interest and adjust lower and upper intensity Hounsfield unit (HU) thresholds until the entire volume was correctly selected.

\section{SENSE Device}

The SENSE device was comprised of two segments; a headset worn by the patient (Figure 1), and the controlling electronics (not shown). These two items were connected by a semi-rigid cable. The headpiece contained 9 circular microwave patch antennae with an operating frequency of $913 \mathrm{MHz}$. The total power radiated for a given antenna when active was $1 \mathrm{~mW}$. 
The antenna array was configured as 3 sagittal arrays of 3 antenna each; one in the midline of the patient's head, and the remaining on the left and right sides respectively. The antennae were offset from direct contact with a given subject's head by a foam insulating pad. All antennae were approximately oriented radially towards the center of the intracranial region. All patient-contacting materials and electronics underwent and passed approved biological and electronic safety testing prior to use.

For a given measurement, one antenna would transmit the incident signal, and the remaining 8 received the altered signal as modified by absorption and scattering from intracranial tissues. In a single measurement, all 9-antenna served as the transmitting antenna, thus yielding 72 total measurements. For a cycle, the measurement would be repeated for 10 iterations. A single cycle took about 40 seconds. The data were stored on a secured internal hard drive of the driving electronics, and were downloaded by study personnel once data acquisition for the given patient was completed. Patients were scanned every 10 minutes during the study period.

\section{SENSE Data}

Methods used in the SENSE algorithm were developed from in vitro and in vivo porcine experiments $(9,13)$. First, for each pair of antennae, the raw voltage data was compared to the first, or baseline, measurement. This value was denoted $\Delta_{\mathrm{TR}}$, where $\mathrm{T}$ is the transmitting antenna and $\mathrm{R}$ is the receiving antenna. Then, for this time point, delta values for all pairs were compared. By comparing the delta values to a set of threshold values, the change was determined to be due to a change in the ICH volume, edema development, movement, or system drift. While the SENSE device can detect changes due to both increases and decreases (due to clot retraction) in hemorrhage size, only increases in hemorrhage volume greater than $3 \mathrm{~mL}$ were considered significant and were denoted as active bleeding.

\section{Results}

\section{Subjects}

A total of 10 patients were enrolled from May through October 2017, and 9 completed the protocol. The average age was 57 years (range: 43-70), and there were 5 female subjects. Details of the ICH locations and volumes are shown in Table 1. Patients were monitored with SENSE for an average of 60 (range: 23-72) hours. There were no Serious Adverse Events. Adverse events were predominantly minor skin and nose irritation from the nosepiece of the headset.

\section{CTs}

The initial head CT for these patients showed an average ICH volume of 24.5 (SD 19.7) $\mathrm{ml}$. Of the 10 patients, 9 completed the protocol. The SENSE data for one patient was lost due to operator error of the device. Of the remaining 9 patients, 2 had a significant expansion of 3.0 and $8.2 \mathrm{ml}$, respectively. The expansion for both patients occurred within 12 hours of onset, and was demonstrated on the 12-hour study CT. 
medRxiv preprint doi: https://doi.org/10.1101/2020.05.25.20109108; this version posted May 26, 2020. The copyright holder for this preprint (which was not certified by peer review) is the author/funder, who has granted medRxiv a license to display the preprint in perpetuity.

\section{SENSE}

As shown in Table 1, the SENSE data was $100 \%$ concordant with the CT results. The SENSE signals showed significant changes in time for the two expansions, and did not show any such changes for the 7 patients who did not experience a hemorrhage expansion.

\section{Discussion}

In summary, the SENSE device was used to safely monitor ICH patients in a clinical environment. In addition, it was able to detect $\mathrm{HE}$ of $\geq 3 \mathrm{ml}$ in this prospective, single-site pilot trial. Significant limitations include the small sample size $n$ of 10 patients, and the single-site limits the generalizability of our results. However, these results are promising, and certainly warrant further study.

Currently, ICH patients are monitored by serial neurologic exam, and neuroimaging. In addition, intracranial pressure monitoring (ICP) is sometimes utilized in a subset of patients (Tuan 2013). However to the authors' knowledge, there are no non-invasive monitors of ICH in current clinical use. In addition, the clinical exam may be difficult in a sedated and/or paralyzed and intubated patient such that a neurological exam is not possible. Also HE can occur in such patients, and may not be detected for hours, depending on the schedule of neuroimaging. There is clearly a clinical need for such a monitor, and the results presented here suggest that RF monitoring may be a useful approach.

\section{Author Contributions Statement}

All authors planned and designed the study. JJ wrote the grant, obtained the data, and performed the data analysis. GJ performed data analysis and drafted the manuscript. OA and ML assisted in grant preparation, and reviewed the manuscript. WK assisted in study design, served as site PI, and reviewed the manuscript.

\section{Funding}

This work was funded by the National Science Foundation under grant SBIR Phase II 1632270.

\section{Conflicts}

JK is an employee of and owns shares of SENS Diagnostics, Inc.

GJ, OA and ML are co-inventors of a patent underlying the SENSE device, and owns shares in SENSE Diagnostics, Inc, WK has no conflicts 
medRxiv preprint doi: https://doi.org/10.1101/2020.05.25.20109108; this version posted May 26, 2020. The copyright holder for this preprint (which was not certified by peer review) is the author/funder, who has granted medRxiv a license to display the preprint in perpetuity.

\section{It is made available under a CC-BY-NC-ND 4.0 International license .}

253

254

255

256

257

258

259

260

261

262

263

264

265

266

267

268

269

270

271

272 
medRxiv preprint doi: https://doi.org/10.1101/2020.05.25.20109108; this version posted May 26, 2020. The copyright holder for this preprint (which was not certified by peer review) is the author/funder, who has granted medRxiv a license to display the preprint in perpetuity.

273

274

275

276

277

278

279

280

281

282 
medRxiv preprint doi: https://doi.org/10.1101/2020.05.25.20109108; this version posted May 26, 2020. The copyright holder for this preprint (which was not certified by peer review) is the author/funder, who has granted medRxiv a license to display the preprint in perpetuity. It is made available under a CC-BY-NC-ND 4.0 International license .

Table 1: ICH Characteristics

\begin{tabular}{|l|l|l|l|l|}
\hline ICH Location & Initial V (ml) & $\mathbf{V ~ ( 1 2 ~ h ) ~}$ & $\mathbf{V}(\mathbf{7 2} \mathbf{~ h )}$ & $\begin{array}{l}\mathbf{1 2} \mathbf{~ h ~ I C H} \\
\text { Expansion }\end{array}$ \\
\hline R BG, Thalamus & 1 & 1 & & \\
\hline L BG, Thalamus, IC & 3.8 & 3.8 & 3.2 & \\
\hline L Lobar & 20.2 & 20.6 & 18 & \\
\hline BG & 22 & 25 & 20 & Y \\
\hline R Lobar & 35.1 & 33.4 & 30.4 & \\
\hline L BG, thalamus, IC & 24.8 & 23.5 & 18.3 & \\
\hline R BS, Cerebellar & 12.7 & 20.9 & & $Y$ \\
\hline L BG & 12.3 & 11.3 & 11.2 & \\
\hline L Lobar & 61.4 & 59.5 & 51.7 & \\
\hline $\begin{array}{l}\text { L BG, Thalamus, IC, } \\
\text { Caudate Nucleus }\end{array}$ & 51.5 & 50.4 & 48.9 & \\
\hline
\end{tabular}

287 
medRxiv preprint doi: https://doi.org/10.1101/2020.05.25.20109108; this version posted May 26, 2020. The copyright holder for this preprint (which was not certified by peer review) is the author/funder, who has granted medRxiv a license to display the preprint in perpetuity.

It is made available under a CC-BY-NC-ND 4.0 International license .

290 Figure 1: SENSE headset piece (controlling electronics not shown). The antenna array (9 total) 291 is contained within the headpiece, along with appropriate wiring. The antenna signals are input and output via a cable (not shown) that communicates with the control box.

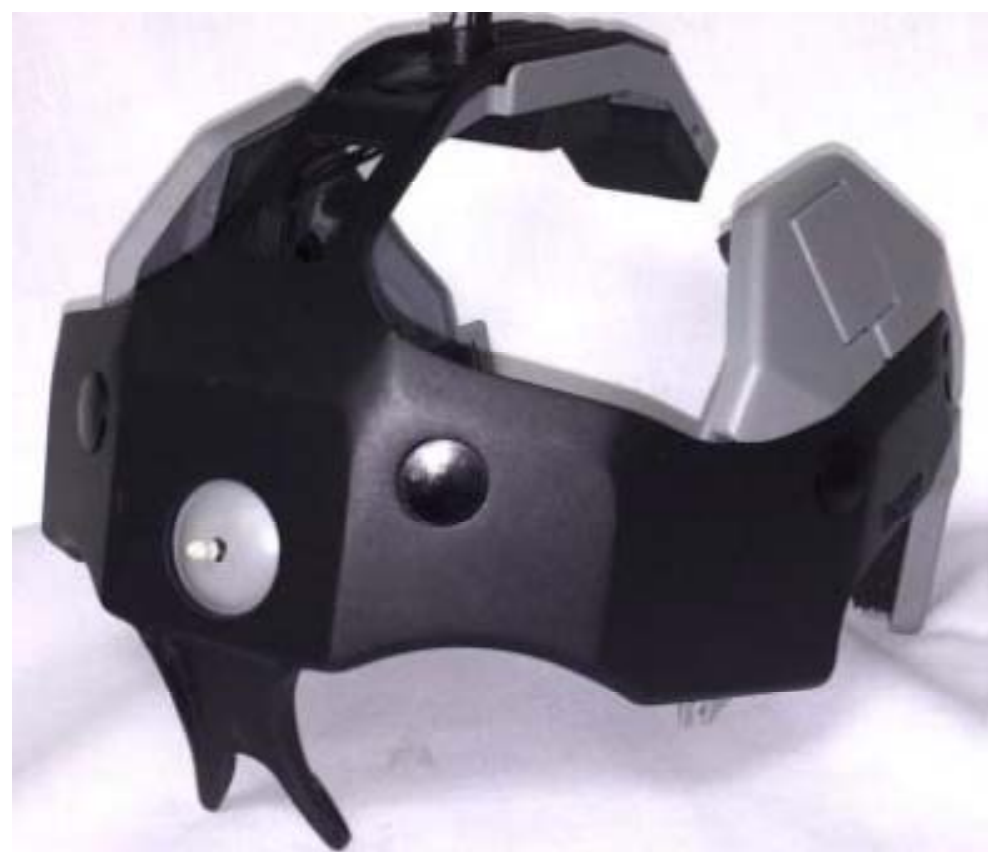


medRxiv preprint doi: https://doi.org/10.1101/2020.05.25.20109108; this version posted May 26, 2020. The copyright holder for this preprint (which was not certified by peer review) is the author/funder, who has granted medRxiv a license to display the preprint in perpetuity.

It is made available under a CC-BY-NC-ND 4.0 International license .

\section{References}

310 1. Caceres JA, Goldstein JN. Intracranial hemorrhage. Emerg Med Clin North Am. 2012;30(3):771-

31194.

312 2. Dastur CK, Yu W. Current management of spontaneous intracerebral haemorrhage. Stroke and

313 Vascular Neurology. 2017;2(1):21.

$3143 . \quad H e r s h$ EH, Gologorsky Y, Chartrain AG, Mocco J, Kellner CP. Minimally Invasive Surgery for

315 Intracerebral Hemorrhage. Current Neurology and Neuroscience Reports

$316 \quad 2018 ; 18(6)(34)$.

317 4. Awad IA, Polster SP, Carrion-Penagos J, Thompson RE, Cao Y, Stadnik A, et al. Surgical

318 Performance Determines Functional Outcome Benefit in the Minimally Invasive Surgery Plus

319 Recombinant Tissue Plasminogen Activator for Intracerebral Hemorrhage Evacuation (MISTIE)

320 Procedure. Neurosurgery. 2019;84(6):1157-68.

321 5. Al-Shahi Salman R, Law ZK, Bath PM, Steiner T, Sprigg N. Haemostatic therapies for acute

322 spontaneous intracerebral haemorrhage. The Cochrane database of systematic reviews.

323 2018;4:Cd005951.

324 6. Davis SM, Broderick J, Hennerici M, Brun NC, Diringer MN, Mayer SA, et al. Hematoma growth is

325 a determinant of mortality and poor outcome after intracerebral hemorrhage. Neurology.

326 2006;66(8):1175-81.

327 7. de Oliveira Manoel AL, Goffi A, Zampieri FG, Turkel-Parrella D, Duggal A, Marotta TR, et al. The

328 critical care management of spontaneous intracranial hemorrhage: a contemporary review. Critical care

329 (London, England). 2016;20:272-.

330 8. Maas MB, Rosenberg NF, Kosteva AR, Bauer RM, Guth JC, Liotta EM, et al. Surveillance

331

332 neuroimaging and neurologic examinations affect care for intracerebral hemorrhage. Neurology. 2013;81(2):107-12.

333 9. Korfhagen JJ, Kandadai MA, Clark JF, Adeoye O, Shaw GJ. A prototype device for non-invasive 334 continuous monitoring of intracerebral hemorrhage. J Neurosci Methods. 2013;213(1):132-7.

335 10. Gabriel S, Lau RW, Gabriel C. The dielectric properties of biological tissues: II. Measurements in the frequency range $10 \mathrm{~Hz}$ to $20 \mathrm{GHz}$. Phys Med Biol. 1996;41(11):2251-69.

11. Griffiths DJ. Introduction to Electrodynamics. 4 ed. Cambridge: Cambridge University Press; 2017.

12. Kothari RU, Brott T, Broderick JP, Barsan WG, Sauerbeck LR, Zuccarello M, et al. The ABCs of measuring intracerebral hemorrhage volumes. Stroke. 1996;27(8):1304-5.

341 13. Kandadai MA, Korfhagen JJ, Beiler S, Beiler C, Wagner K, Adeoye OM, et al. In vivo testing of a non-invasive prototype device for the continuous monitoring of intracerebral hemorrhage. J Neurosci Methods. 2014;235:117-22.

344 14. Klahr AC, Kate M, Kosior J, Buck B, Shuaib A, Emery D, et al. Early hematoma retraction in 345 intracerebral hemorrhage is uncommon and does not predict outcome. PloS one.

346 2018;13(10):e0205436-e. 
medRxiv preprint doi: https://doi.org/10.1101/2020.05.25.20109108; this version posted May 26, 2020. The copyright holder for this preprint (which was not certified by peer review) is the author/funder, who has granted medRxiv a license to display the preprint in perpetuity.

\section{It is made available under a CC-BY-NC-ND 4.0 International license .}

